\title{
Modeling of the Electric Field in a Hypersonic Rarefied Flow
}

\author{
Erin D. Farbar* and Iain D. Boyd ${ }^{\dagger}$ \\ Department of Aerospace Engineering, University of Michigan, Ann Arbor, MI 48109
}

\begin{abstract}
During the hypersonic reentry of a vehicle into the Earth's atmosphere, the collisions between neutral particles are of sufficient energy to cause ionizing reactions and produce a weakly ionized plasma. This weak plasma is created behind the strong bow shock that forms in front of the reentry vehicle. It interferes with communication to the vehicle from ground stations, and can affect the magnitude of convective and radiative heat transfer to the vehicle surface. The presence of this weak plasma necessitates the existence of an electric field in the shock layer to accelerate the charged particles. In this study, the structure of the self-induced electric field in a rarefied reentry flow is examined using a Direct Simulation Monte Carlo solver that is coupled to a Particle in Cell solver. Computations are performed for a one dimensional model of the stagnation streamline of the flow formed in front of a blunt body reentering the Earth's atmosphere. The model parameters are chosen to produce a flow field structure similar to that experienced by the FIRE II reentry vehicle at an altitude of $85 \mathrm{~km}$ in its reentry trajectory. This is accomplished in a computationally tractable manner by varying the freestream density, the diameters of the particles, and the electron mass from the values at the actual FIRE II flight conditions. The flow field results are compared to results obtained using an approximate DSMC method used to incorporate the effect of the electric field on the structure of a hypersonic shock layer.
\end{abstract}

\section{Nomenclature}

E electric field in $\mathrm{V} / \mathrm{m}$

q elementary charge in $\mathrm{C}$

$\mathrm{m} \quad$ particle mass in $\mathrm{kg}$

M Mach number

$\mathrm{n} \quad$ number density in $\mathrm{m}^{-3}$

$\mathrm{T}$ temperature in $\mathrm{K}$

$\mathrm{U}, \mathrm{u}$ velocity in $\mathrm{m} / \mathrm{s}$

$\Delta \mathrm{t}$ simulation time step in $\mathrm{s}$

$\Delta \mathrm{x}$ grid spacing in $\mathrm{m}$

$\varepsilon_{o} \quad$ permittivity of free space in $\mathrm{F} / \mathrm{m}$

$\lambda_{D} \quad$ Debye length in $\mathrm{m}$

$\phi \quad$ electric potential in $\mathrm{V}$

$\rho \quad$ mass density in $\mathrm{kg} / \mathrm{m}^{3}$

\section{Subscripts}

e electron value

i ion value

p particle value

w wall value

z flow direction

$\infty \quad$ freestream value

*Graduate Student, Student Member AIAA. Email: efarbar@umich.edu

${ }^{\dagger}$ Professor, Associate Fellow AIAA. Email: iainboyd@umich.edu 


\section{Introduction}

The flow field about a vehicle undergoing a high energy reentry into the atmosphere experiences collisions at energies sufficient to ionize particles. As a result, a weakly ionized plasma surrounds the vehicle. A thorough consideration of the physical phenomena associated with ionization is important for predicting the condition of communications blackout, and in general for modeling the flow field structure. This work addresses the computational treatment of ionization phenomena during the rarefied, noncontinuum portion of the reentry trajectory.

One such physical phenomenon is the ambipolar electric field that exists within a plasma, created by the large scale space-charge distribution of the plasma. This field is present to enforce the condition of charge neutrality in the bulk plasma, and within the bulk plasma the effect of the ambipolar electric field is to cause the ions and electrons to diffuse at the same average rate. In the context of the geometry of the flow field around a typical reentry vehicle, the ambipolar field does not exist very near to solid boundaries, nor near the interface of the weak plasma and the ambient neutral gas. In these regions, the ambipolar assumption is not valid and charge neutrality is not enforced.

Some researchers have reported results obtained from models of the ambipolar electric field of a weakly ionized reentry plasma in the literature. ${ }^{1-4}$ The common assumption used in all of these models is that the average velocities of the ions and electrons are equal everywhere in the domain, in order to either calculate the electric field or to model its effect on the flow structure. In all but the simulations by Taylor et al., ${ }^{1}$ the electrons were tied in some manner to the ions and not allowed to move freely throughout the domain. In the method introduced by Boyd ${ }^{2}$ to model the electric field effects, the velocity components of the charged particles were not modified to include the acceleration due to the field. The result of the various simplifications made in these previous models is that they all fail to model the electric field generated in a hypersonic reentry flow field in it's entirety and in a self-consistent manner.

The goal of this work is to capture all of the physics associated with the self-induced electric field and to determine what effect, if any, the use of simplified models has on the flow field variables of interest. This is accomplished using a hybrid Direct Simulation Monte Carlo (DSMC) ${ }^{5}$-Particle-in-Cell (PIC) ${ }^{6}$ method. Flow field results are obtained for a simplified one dimensional model of the stagnation streamline of a rarefied hypersonic shock layer. The ambient flow conditions used in the model have been designed to produce a flow field that is similar to that experienced by the FIRE II Earth reentry vehicle ${ }^{7}$ at an altitude of $85 \mathrm{~km}$ in its reentry trajectory. Thus, the results and conclusions produced from this study are applicable to real Earth reentry flight conditions.

The details of both the numerical methods used in this analysis and of the simplified shock layer model are presented first. Next, two sets of results for the simplified model obtained using both the DSMC and DSMC-PIC methods are compared and discussed. The first set is obtained using the real electron mass and a low freestream density. The second set is obtained at a freestream density that is three orders of magnitude larger, and the electron mass is also increased by three orders of magnitude. Lastly, conclusions and suggestions for further work are provided.

\section{Numerical method}

In order to model the self-induced electric field created in the shock layer in a self-consistent manner, the DSMC code is tightly coupled with a PIC solver to compute the plasma potential and thus the electric field. Due to the PIC requirement that the cell sizes used in the simulation be smaller than a Debye length, the hybrid DSMC-PIC simulation of the strong shock wave is performed in one dimension to ensure that it is computationally tractable. The code is parallelized using the Message Passing Interface libraries.

\section{II.A. DSMC module}

The DSMC module uses a code called MONACO, developed specifically for hypersonic flow simulations. Models are implemented in the code for rotational ${ }^{8}$ and vibrational energy exchange,${ }^{9}$ and chemical reactions in this study are simulated using the Total Collision Energy model. ${ }^{10}$

The method developed by Bird for performing a one dimensional DSMC simulation of the stagnation streamline of a blunt body flow is used. The basic idea of the method is to exploit the fact that along the stagnation streamline of such flows only flow field gradients in the axial direction exist. Particles can thus be removed from random locations downstream of the shock to produce a one dimensional simulation 
of the flow along the stagnation streamline. Figures 1 and 2 show the translational temperature and mass density along the stagnation streamline of an axisymmetric DSMC simulation of the flow about the FIRE II reentry vehicle at an altitude of $85 \mathrm{~km}$. Also shown on these figures are the results obtained from the one dimensional DSMC simulation for the same trajectory point. It is clear that Bird's method produces consistent results. More details of this method are found in Ref. 11.

Because electrons are much lighter than ions and neutral particles, they possess larger thermal velocities. In order to retard the motion of the electrons, a space-charge distribution is set up in the plasma that creates an electric field. As a result, the electrons are constrained to diffuse at the same rate as the ions in the bulk plasma region; this phenomenon is called ambipolar diffusion. When computing a flow field solution using only the DSMC module, quasi-neutrality of the plasma is enforced by invoking the assumption of ambipolar diffusion everywhere in the simulation domain. The use of this assumption in the DSMC module means that the plasma potential and electric fields do not have to be computed explicitly. In the implementation used here, the average ion velocity is computed in each cell, and the electrons are moved with this average velocity while retaining their large thermal velocity components. The collision algorithm is subcycled so that the high collision rate of the electrons with heavy particles is accurately represented. Further details of this model are found in Ref. 12 .

\section{II.B. PIC module}

The charge-in-cloud (CIC) interpolation method ${ }^{6}$ is used to resolve the space-charge density at the nodes of the computational grid in the PIC routine using the electron and ion simulator particles in each cell. The space charge density is then used as the source term in the solution of the electrostatic potential equation given by Equation 1. The electric field is computed from the potential using Equation 2 and values of the field are calculated at the charged particle locations using the CIC method.

Assuming that the instantaneous electric field is constant during a simulation time step, the average velocity of a charged particle during one iteration of the simulation is computed using Equation 3 . This is the velocity that charged particles are moved with during the move portion of the DSMC algorithm. The velocity increment imposed on a particle due to its acceleration in the electric field is given by Equation 4 and is added to the axial velocity components of the charged particles at each time step.

The boundary condition for the potential field at the freestream is of von Neumann type, and set to $\mathrm{E}_{z}=\mathrm{d} \phi / \mathrm{dz}=0 \mathrm{~V} / \mathrm{m}$ in order to enforce a zero electric field condition in the far-field. The boundary condition for the potential field at the vehicle surface is fixed at $\phi=0 \mathrm{~V}$, and current is permitted to flow to the surface.

$$
\begin{gathered}
\frac{d^{2} \phi}{d z^{2}}=-\frac{q}{\varepsilon_{o}}\left(n_{i}-n_{e}\right) \\
E_{z}=-\frac{d \phi}{d z} \\
\overline{u_{p}^{\prime}}=u_{p}+\frac{1}{2} \Delta u_{p} \\
\Delta u_{p}=\frac{q}{m} E_{z} \Delta t
\end{gathered}
$$

\section{Shock layer model}

The simplified shock layer model is a one dimensional representation of the stagnation streamline of a hypersonic shock layer that is formed during the reentry of an axisymmetric blunt body into the atmosphere at a negligible angle of attack. The purpose of the simplified model is to provide a test case that allows the structure of a shock layer to be simulated using the DSMC-PIC method, but at a lower computational cost than would be required to simulate a shock layer formed at Earth reentry conditions. The use of this model provides valuable insight into the fundamental physics associated with this type of flow field.

The flight condition of the FIRE II vehicle at an altitude of $85 \mathrm{~km}$ during the reentry trajectory is summarized in Table 1. The freestream of the simplified shock layer model has the species composition of air at $85 \mathrm{~km}$, however the overall density is reduced to produce a more tractable computation. As in the FIRE 
II case, the freestream velocity is $11.37 \mathrm{~km} / \mathrm{s}$ and the freestream temperature is $212 \mathrm{~K}$, yielding a freestream Mach number of 39 . The wall temperature is set to $460 \mathrm{~K}$ and the wall is diffuse and fully catalytic to the recombination of charged species but not to atoms. In order to produce a shock stand-off distance and mean free path typical of a reentry vehicle in the rarefied portion of the atmosphere, the diameters of the simulator particles are increased from the baseline values given in Table 2 by a factor of $\sqrt{1 \times 10^{6}}$ in the first simulation and a factor of $\sqrt{1000}$ in the second. The chemical reaction rate data used in previous DSMC analyses of the FIRE II reentry trajectory are used, however the rates are increased by a factor of $5 \times 10^{5}$ in the first simulation and a factor of $5 \times 10^{2}$ in the second to yield a degree of ionization close to that computed for the FIRE II $85 \mathrm{~km}$ trajectory point. ${ }^{12}$ The baseline chemical reaction data is given in Table 3 . In the second simulation, the electron mass is increased by three orders of magnitude to yield $\mathrm{m}_{N^{+}} / \mathrm{m}_{e} \sim 25$.

Comparisons of the mole fractions of each species predicted using the DSMC method along the stagnation streamline for both the shock layer model and the FIRE II $85 \mathrm{~km}$ case are given in Figures 3 and 4 . The shock standoff distance is slightly larger in the FIRE II case, and the degree of ionization is slightly higher. Overall, the structure of the flow in the shock layer model is sufficiently similar to that surrounding the FIRE II vehicle at an altitude of $85 \mathrm{~km}$ to draw useful conclusions from the present results.

A schematic of the shock layer model is given in Figure 5.

\section{III.A. Computational parameters}

The grids used the simulations have 500 and 16000 cells, respectively. The grid is constructed in such a way that a ratio of approximately $\lambda_{D} / \Delta \mathrm{x}=5$ is satisfied at each cell in the domain. In some regions of the domain the cells are much smaller than a mean free path due to this requirement. This is illustrated in Figure 6 , which shows the Debye length and mean free path along the stagnation streamline for the simulation with 16000 cells.

The timestep is dictated by the minimum cell crossing time of the electron particles, which is much less than the plasma period. The weight factor of the simulator particles is selected to yield approximately 10 charged particles per cell in the peak plasma density region. The total number of simulated particles varies from 300000 to 3000000 in these simulations. The simulation has converged when the number of simulator particles in the domain, the total energy in the domain and the current to the vehicle surface reach a steady state. An example of one such convergence history is shown in Figure 7. These simulations require 6000000 and 9000000 timesteps to reach steady state, respectively. Once a steady state is reached, a minimum of 50000 sampling iterations are performed.

The total simulation time for the DSMC-PIC cases ranges from $60 \mathrm{CPU}$ hours to $3500 \mathrm{CPU}$ hours on a maximum of 15 processors. For the simulation involving 3000000 particles, the parallel efficiency of the one dimensional DSMC-PIC solver is $67 \%$ and deviates strongly from the ideal value when more than 15 processors are used. Comparatively, the parallel efficiency of the original DSMC code is $77 \%$ when running the same simulation in two dimensions. The reduction in parallel efficiency from the ideal value occurs as a result of many factors: the nature of the method used to remove particles in the one dimensional DSMC algorithm, the method used to solve the electrostatic potential equation, and the increase in communication time required in the particle movement portion of the basic DSMC algorithm as the number of particles per processor decreases.

\section{Results and Discussion}

The results of two different shock layer simulations are presented here. The first case uses a freestream density of $2 \times 10^{14} \mathrm{~m}^{-3}$ and the actual electron mass. The second case uses a freestream density of $2 \times 10^{17} \mathrm{~m}^{-3}$ and $1000 \times m_{e}$.

\section{IV.A. Real electron mass}

Figure 8 shows the predicted electric and potential fields along the stagnation streamline for the simulation with a freestream density of $2 \times 10^{14} \mathrm{~m}^{-3}$ and the actual electron mass. Figure 9 shows the velocity increment that is applied to the ions and electrons at each time step as a result of their response to the electric field. As expected, the ambipolar electric field develops in the shock layer, while near the vehicle surface a very strong electric field develops in the sheath. The width of the sheath is an order of magnitude larger than the mean free path of the ions in the sheath region. The magnitude of the potential drop in the sheath is 
slightly larger than the value of $5 \mathrm{~V}$ predicted by collisionless sheath theory, owing to the collisionality of the sheath.

Figure 10 shows the temperatures predicted using both the DSMC-PIC and DSMC methods along the stagnation streamline of the flow. The significant differences in these two sets of results are in the predicted electron translational temperature in the regions upstream of the shock and close to the vehicle surface. The DSMC-PIC method predicts a greater electron temperature upstream of the shock because the electrons are not constrained to move with the ions. The electrons that manage to escape the ambipolar electric field in this region are those with large negative velocity components and the distribution function becomes bimodal in this region, leading to a greater translational temperature. ${ }^{13}$ In the sheath region, the electrons are decelerated by the electric field and very few reach the vehicle surface to recombine. The majority of electrons have their direction of travel reversed, leading to a temperature profile that is flatter than that predicted by the DSMC method.

The strongest assumption made when using the DSMC method with the ambipolar diffusion model is that the electrons possess the same average velocity as the ions. When the ambipolar diffusion model is used, the electron particles are moved with the average velocity of the ions but their individual velocity components are retained. Figure 11 shows the average velocities of the charged species along the stagnation streamline computed using both the DSMC-PIC method and the DSMC method with the ambipolar diffusion model. The DSMC-PIC results show that the average velocity of the electrons is negative in the region upstream of the shock and is not equal to the average velocity of the ions in that region. Figure 12 shows the average ion and electron velocities computed using both methods in the region downstream of the shock. In the shock layer, the DSMC-PIC method predicts a lower average ion velocity than the DSMC method because the ions are decelerated by the negative electric field in this region. The average velocity of the ions increases as they travel towards the wall and are accelerated by the strong positive electric field in the sheath. Very close to the vehicle surface the ion velocity begins to decrease due to the collisionality of the sheath. The average electron velocity increases strongly near the vehicle surface for two reasons. The vehicle surface acts as a sink to electrons, so there are very few electrons in this region with negative velocity. Secondly, the majority of electrons do not possess sufficient energy to traverse the potential drop in the sheath. Those that do reach the vehicle surface are at the tail of the electron energy distribution function and have very high energies. The DSMC-PIC results show that the average velocity of the electrons is not equal to that of the ions in the sheath region, as expected.

Figure 13 shows the number densities of electrons and ions along the stagnation streamline predicted by both methods. This figure also shows the magnitude of the charge separation predicted by the DSMC-PIC method. The DSMC-PIC method predicts an increase relative to the DSMC results in both the ion and the electron number density in the region upstream of the shock layer. In this region, the charge separation is no longer large enough to create an electric field sufficient to restrain the electrons, and the flow transitions to free diffusion. The DSMC-PIC method predicts a decrease in both the ion and electron number density in the sheath region as expected, except very near the wall where the number density of the ions peaks abruptly. This phenomenon is due to the collisionality of the sheath. Ions at this point in the sheath have experienced at least one collision, which causes a decrease in the macroscopic average ion velocity, as shown in Figure 12. In order to enforce species continuity, the number density of ions correspondingly increases in this region.

Table 4 shows a comparison of heat flux quantities obtained from the DSMC and DSMC-PIC solutions. The contribution to the surface heat flux due to charged particle impact predicted by the DSMC-PIC model is larger than that predicted by the DSMC model, and comprises $11 \%$ of the total heat flux. The DSMC-PIC model predicts an increase of $13 \%$ in the total heat flux to the vehicle surface for these freestream conditions. The increase in the heat flux from charged particle impact is largely due to the acceleration of the ions in the sheath near the vehicle surface. The increase in the total heat flux is the result of both the acceleration of ions in the sheath, and a small increase in the energy of the neutral particles near the wall due to collisions with the ions in the sheath.

\section{IV.B. Artificial electron mass}

Figure 14 shows the predicted electric and potential fields along the stagnation streamline for the shock layer simulation with a freestream density of $2 \times 10^{17} \mathrm{~m}^{-3}$ and $1000 \times m_{e}$. Figure 15 shows the velocity increment that is applied to the ions and electrons at each time step as a result of their acceleration in the electric

field. Qualitatively, the structure of the predicted electric field is the same in this case as in the previous 
case. Due to the heavier electron particles, the potential drop in the sheath is on the order of $1 \mathrm{~V}$ rather than $6 \mathrm{~V}$. The sheath is predicted to be much thinner than in the previous case, as the sheath width scales with $1 / \sqrt{n_{e}}$. The thinness of the sheath results in a much stronger electric field in the sheath region in this case. The ambipolar electric field in the vicinity of the shock is predicted to be slightly larger than that in the previous case, as this region of the electric field scales with $\ln \left(n_{e}\right) \cdot{ }^{14}$

Figure 16 shows the temperatures predicted using both the DSMC-PIC and DSMC methods along the stagnation streamline of the flow. The significant difference in these two sets of results is in the predicted electron translational temperature upstream of the shock. As in the previous case, the DSMC-PIC method predicts a greater electron temperature upstream of the shock because the electrons are not constrained to move with the ions. Because the sheath is thinner and the electrons travel through a smaller potential drop than in the previous case, there is little change in the electron temperature in the sheath region when the DSMC-PIC method is used. If the correct electron mass were used in this case, the electron temperature profile would flatten over the width of the sheath region, as was observed in the previous case.

The trends shown in the previous case for the average velocities of charged species along the stagnation streamline are also observed for this set of free stream conditions. The average electron velocity is large and negative in the region upstream of the shock, and not equal to the average ion velocity in that region. In the sheath the average electron velocity is large, positive, and not equal to the average ion velocity.

Figure 17 shows the number densities of electrons and ions along the stagnation streamline predicted by both methods. This figure also shows the magnitude of the charge separation predicted by the DSMCPIC method. As in the previous case, the DSMC-PIC method predicts an increase relative to the DSMC results in both the ion and the electron number density in the region upstream of the shock layer where the flow transitions to free diffusion. Figure 18 shows the number densities and charge separation predicted by the DSMC-PIC method in the sheath region. There is a monotonic decrease in both the ion and electron number density in the sheath region as expected. The abrupt increase in the ion density near the wall does not appear in this case, indicating that this sheath is not strongly collisional. If the correct electron mass were used in this case the potential drop in the sheath would increase, leading to an increase in the strength of the electric field. This would cause a larger decrease in the electron number density in the sheath region, as well as an increase in the electron temperature as discussed previously. Since the sheath width scales with the Debye length, which in turn scales as $\lambda_{D} \sim \sqrt{\frac{T_{e}}{n_{e}}}$, it is expected that the sheath would become larger and also collisional at this flow condition if the correct electron mass were used in the simulation. Thus, we expect that the peak in ion number density in the sheath region observed in the previous case would also occur at this freestream density.

Table 5 shows a comparison of heat flux quantities obtained from the DSMC and DSMC-PIC solutions. The contribution to the surface heat flux due to charged particle impact predicted by the DSMC-PIC model is larger than that predicted by the DSMC model, and composes $10 \%$ of the total heat flux. The DSMC-PIC model predicts an increase of $16 \%$ in the total heat flux to the vehicle surface for these freestream conditions. The increase in total heat flux occurs as a result of the same mechanisms discussed previously.

\section{Conclusions}

We estimate the time required to complete a DSMC-PIC calculation along the stagnation streamline of the flow field about the FIRE II vehicle at an altitude of $85 \mathrm{~km}$ to be $1300000 \mathrm{CPU}$ hours, or $55000 \mathrm{CPU}$ days. This estimate is for a computation using an artificially heavy electron species with $1000 \times m_{e}$ and accounts for the parallel efficiency of the current DSMC-PIC code. A computation with the actual electron mass would require $1800000 \mathrm{CPU}$ days with our current resources. The computational requirements could be reduced by parallelizing the code for use with a shared memory system. This would increase the parallel efficiency of the particle removal algorithm used to compute the 1D simulation. Additionally, the efficiency of the matrix inversion algorithm used to solve the electrostatic potential equation could be improved. Lastly, using smaller particle weight factors for the trace charged species would decrease the computational requirements.

The use of the DSMC-PIC method allows rarefied Earth reentry flow fields to be modeled in a physically complete and consistent way. Compared to the DSMC results, the method predicts differences in the electron translational temperature, the number densities of charged species in the sheath region and downstream of the shock location, and the heat flux to the vehicle surface. For Earth entries where a minor portion of the vehicle heat load occurs in the rarefied portion of the atmosphere, the predicted differences appear to be 
insignificant from an aerothermodynamics standpoint. The results from this study indicate that the DSMCPIC method would also predict insignificant changes relative to results obtained using the DSMC method at the actual FIRE II $85 \mathrm{~km}$ flight condition. These results indicate that the ambipolar diffusion assumption is valid for use within the DSMC method for the computation of rarefied reentry flow fields when the majority of the vehicle heating occurs in the continuum region of the Earth's atmosphere.

For an Earth entry mission where the vehicle spends a large amount of time in the rarefied region of the atmosphere, the predicted increase in the overall heat flux may affect the vehicle heat shield design. In the case of an atmospheric entry where radiative heat transfer is a significant portion of the overall heat transfer to the vehicle surface, the predicted increases in electron translational temperature may play an important role in the prediction of vehicle heating. Therefore for the computation of entries into the Martian atmosphere or a skip reentry, for example, the use of the DSMC-PIC method may be warranted.

\section{Acknowledgments}

The authors gratefully acknowledge the financial support provided by NASA grant NCC3-989. E. Farbar also gratefully acknowledges the financial support of the National Research Council of Canada and the Zonta International Foundation.

\section{References}

\footnotetext{
${ }^{1}$ Taylor, J. C., Carlson, A. B., and Hassan, H. A., "Monte Carlo Simulation of Radiating Re-entry Flows," Journal of Thermophysics and Heat Transfer, Vol. 8, No. 3, 1994, pp. 478-485.

${ }^{2}$ Boyd, I. D., Trumble, K., and Wright, M. J., "Nonequilibrium Particle and Continuum Analyses of Stardust Entry for Near-Continuum Conditions," 38th AIAA Aerospace Sciences Meeting and Exhibit, AIAA Paper 2007-4543, January 2007.

${ }^{3}$ Bird, G. A., "Nonequilibrium Radiation During Re-entry at $10 \mathrm{~km} / \mathrm{s}$," 22nd AIAA Thermophysics Conference, AIAA Paper 87-1543, June 1987.

${ }^{4}$ Gallis, M. A. and Harvey, J. K., "Ionization Reactions and Electric Fields in Plane Hypersonic Shock Waves," Rarefied Gas Dynamics, Vol. 160 of Progress in Astronautics and Aeronautics, AIAA, New York, 1992, pp. $234-244$.

${ }^{5}$ Bird, G. A., Molecular Gas Dynamics and the Direct Simulation of Gas Flows, Oxford Science Publications, 1994.

${ }^{6}$ Hockney, R. W. and Eastwood, J. W., Computer Simulation Using Particles, McGraw-Hill Inc., 1981.

${ }^{7}$ Cornette, E. S., "Forebody Temperatures and Calorimeter Heating Rates Measured During Project Fire II Reentry at 11.35 Kilometers Per Second," Tech. Rep. NASA TM X-1305, Langley Research Center, 1966.

${ }^{8}$ Boyd, I. D., "Rotational-translational Energy Transfer in Rarefied Nonequilibrium Flows," Physics of Fluids, Vol. 2, No. 3, 1989, pp. 447-452.

${ }^{9}$ Boyd, I. D., "Analysis of Vibrational-translational Energy Transfer Using the Direct Simulation Monte Carlo Method," Physics of Fluids, Vol. 3, No. 7, 1991, pp. 1785-1791.

${ }^{10}$ Bird, G. A., "Monte Carlo Simulation in an Engineering Context," Rarefied Gas Dynamics, edited by S. S. Fisher, Vol. 74 of Progress in Astronautics and Aeronautics, AIAA, New York, 1981, pp. 239-255.

${ }^{11}$ Bird, G. A., "Direct Simulation of Typical AOTV Entry Flows," AIAA/ASME 4th Joint Thermophysics and Heat Transfer Conference, AIAA Paper 86-1310, June 1986.

${ }^{12}$ Farbar, E. D. and Boyd, I. D., "Simulation of Fire II Reentry Flow Using the Direct Simulation Monte Carlo Method," 40th AIAA Thermophysics Conference, AIAA Paper 2008-4103, June 2008.

${ }^{13}$ Farbar, E. D. and Boyd, I. D., "Self-Consistent Simulation of the Electric Field in a Rarefied Hypersonic Shock Layer," 41st AIAA Thermophysics Conference, AIAA Paper 2009-4309, June 2009.

${ }^{14}$ Mitchner, M. and Charles H. Kruger, J., Partially Ionized Gases, Wiley-Interscience, 1973.
} 
Table 1: Flow conditions for Project FIRE II at $85 \mathrm{~km}$.

\begin{tabular}{lc}
\hline \hline Property & $1631 \mathrm{~s}$ \\
\hline Altitude & $84.6 \mathrm{~km}$ \\
$\rho_{\infty}$ & $9.15 \times 10^{-6} \mathrm{~kg} / \mathrm{m}^{3}$ \\
$\mathrm{U}_{\infty}$ & $11.37 \mathrm{~km} / \mathrm{s}$ \\
$\mathrm{T}_{\infty}$ & $212 \mathrm{~K}$ \\
$\mathrm{~T}_{\text {wall }}$ & $460 \mathrm{~K}$ \\
$\mathrm{R}_{n}$ & $0.9347 \mathrm{~m}$ \\
$\mathrm{Kn}_{\infty}$ & 0.01 \\
\hline \hline
\end{tabular}

Table 2: Baseline parameters used in the VHS model.

\begin{tabular}{lc}
\hline \hline Parameter & Baseline value \\
\hline$\omega$ & 0.20 \\
$\mathrm{~T}_{\text {ref }}$ & $288 \mathrm{~K}$ \\
$\mathrm{~d}_{N_{2}}$ & $4.07 \times 10^{-10} \mathrm{~m}$ \\
$\mathrm{~d}_{O_{2}}$ & $3.96 \times 10^{-10} \mathrm{~m}$ \\
$\mathrm{~d}_{N O}$ & $4.00 \times 10^{-10} \mathrm{~m}$ \\
$\mathrm{~d}_{N}$ & $3.00 \times 10^{-10} \mathrm{~m}$ \\
$\mathrm{~d}_{O}$ & $3.00 \times 10^{-10} \mathrm{~m}$ \\
$\mathrm{~d}_{N_{2}^{+}}$ & $4.07 \times 10^{-10} \mathrm{~m}$ \\
$\mathrm{~d}_{O_{2}^{+}}$ & $3.96 \times 10^{-10} \mathrm{~m}$ \\
$\mathrm{~d}_{N O^{+}}$ & $4.00 \times 10^{-10} \mathrm{~m}$ \\
$\mathrm{~d}_{N^{+}}$ & $3.00 \times 10^{-10} \mathrm{~m}$ \\
$\mathrm{~d}_{O^{+}}$ & $3.00 \times 10^{-10} \mathrm{~m}$ \\
$\mathrm{~d}_{e}$ & $1.00 \times 10^{-10} \mathrm{~m}$ \\
\hline \hline
\end{tabular}


Table 3: Baseline reaction rate coefficients in $\mathrm{m}^{3} / \mathrm{molecule} / \mathrm{s}$.

\begin{tabular}{|c|c|c|}
\hline Number & Reaction & Rate Coefficient \\
\hline $1 \mathrm{M}$ & $\mathrm{N}_{2}+\mathrm{M} \rightarrow \mathrm{N}+\mathrm{N}+\mathrm{M}$ & $1.162 \times 10^{-8} \mathrm{~T}^{-1.6} \exp (-113200 / \mathrm{T})$ \\
\hline $1 \mathrm{MB}$ & $\mathrm{N}+\mathrm{N}+\mathrm{M} \rightarrow \mathrm{N}_{2}+\mathrm{M}$ & $5.691 \times 10^{-40} \mathrm{~T}^{-1.6}$ \\
\hline $1 \mathrm{~A}$ & $\mathrm{~N}_{2}+\mathrm{A} \rightarrow \mathrm{N}+\mathrm{N}+\mathrm{A}$ & $4.980 \times 10^{-8} \mathrm{~T}^{-1.6} \exp (-113200 / \mathrm{T})$ \\
\hline $1 \mathrm{AB}$ & $\mathrm{N}+\mathrm{N}+\mathrm{A} \rightarrow \mathrm{N}_{2}+\mathrm{A}$ & $1.706 \times 10^{-39} \mathrm{~T}^{-1.6}$ \\
\hline $1 \mathrm{E}$ & $\mathrm{N}_{2}+\mathrm{E}^{-} \rightarrow \mathrm{N}+\mathrm{N}+\mathrm{E}^{-}$ & $4.980 \times 10^{-6} \mathrm{~T}^{-1.6} \exp (-113200 / \mathrm{T})$ \\
\hline $2 \mathrm{M}$ & $\mathrm{O}_{2}+\mathrm{M} \rightarrow \mathrm{O}+\mathrm{O}+\mathrm{M}$ & $3.321 \times 10^{-9} \mathrm{~T}^{-1.5} \exp (-59400 / \mathrm{T})$ \\
\hline $2 \mathrm{MB}$ & $\mathrm{O}+\mathrm{O}+\mathrm{M} \rightarrow \mathrm{O}_{2}+\mathrm{M}$ & $6.305 \times 10^{-44} \mathrm{~T}^{-0.5}$ \\
\hline $2 \mathrm{~A}$ & $\mathrm{O}_{2}+\mathrm{A} \rightarrow \mathrm{O}+\mathrm{O}+\mathrm{A}$ & $1.660 \times 10^{-8} \mathrm{~T}^{-1.5} \exp (-59400 / \mathrm{T})$ \\
\hline $2 \mathrm{AB}$ & $\mathrm{O}+\mathrm{O}+\mathrm{A} \rightarrow \mathrm{O}_{2}+\mathrm{A}$ & $1.905 \times 10^{-43} \mathrm{~T}^{-0.5}$ \\
\hline $3 \mathrm{M}$ & $\mathrm{NO}+\mathrm{M} \rightarrow \mathrm{N}+\mathrm{O}+\mathrm{M}$ & $8.302 \times 10^{-15} \exp (-75500 / \mathrm{T})$ \\
\hline $3 \mathrm{MB}$ & $\mathrm{N}+\mathrm{O}+\mathrm{M} \rightarrow \mathrm{NO}+\mathrm{M}$ & $1.583 \times 10^{-43} \mathrm{~T}^{-0.5}$ \\
\hline $3 \mathrm{~A}$ & $\mathrm{NO}+\mathrm{A} \rightarrow \mathrm{N}+\mathrm{O}+\mathrm{A}$ & $1.826 \times 10^{-13} \exp (-75500 / \mathrm{T})$ \\
\hline $3 \mathrm{AB}$ & $\mathrm{N}+\mathrm{O}+\mathrm{A} \rightarrow \mathrm{NO}+\mathrm{A}$ & $3.180 \times 10^{-43} \mathrm{~T}^{-0.5}$ \\
\hline $4 \mathrm{~F}$ & $\mathrm{O}+\mathrm{NO} \rightarrow \mathrm{N}+\mathrm{O}_{2}$ & $1.389 \times 10^{-17} \exp (-19700 / \mathrm{T})$ \\
\hline $4 \mathrm{~B}$ & $\mathrm{~N}+\mathrm{O}_{2} \rightarrow \mathrm{O}+\mathrm{NO}$ & $4.601 \times 10^{-15} \mathrm{~T}^{-0.546}$ \\
\hline $5 \mathrm{~F}$ & $\mathrm{O}+\mathrm{N}_{2} \rightarrow \mathrm{N}+\mathrm{NO}$ & $1.069 \times 10^{-12} \mathrm{~T}^{-1.000} \exp (-37500 / \mathrm{T})$ \\
\hline $5 \mathrm{~B}$ & $\mathrm{~N}+\mathrm{NO} \rightarrow \mathrm{O}+\mathrm{N}_{2}$ & $4.059 \times 10^{-12} \mathrm{~T}^{-1.359}$ \\
\hline $6 \mathrm{~F}$ & $\mathrm{~N}+\mathrm{N} \rightarrow \mathrm{N}_{2}^{+}+\mathrm{E}^{-}$ & $3.387 \times 10^{-17} \exp (-67700 / \mathrm{T})$ \\
\hline $6 \mathrm{~B}$ & $\mathrm{~N}_{2}^{+}+\mathrm{E}^{-} \rightarrow \mathrm{N}+\mathrm{N}$ & $7.274 \times 10^{-12} \mathrm{~T}^{-0.650}$ \\
\hline $7 \mathrm{~F}$ & $\mathrm{O}+\mathrm{O} \rightarrow \mathrm{O}_{2}^{+}+\mathrm{E}^{-}$ & $1.859 \times 10^{-17} \exp (-81200 / \mathrm{T})$ \\
\hline $7 \mathrm{~B}$ & $\mathrm{O}_{2}^{+}+\mathrm{E}^{-} \rightarrow \mathrm{O}+\mathrm{O}$ & $1.453 \times 10^{-4} \mathrm{~T}^{-2.412}$ \\
\hline $8 \mathrm{~F}$ & $\mathrm{~N}+\mathrm{O} \rightarrow \mathrm{NO}^{+}+\mathrm{E}^{-}$ & $8.766 \times 10^{-18} \exp (-32000 / \mathrm{T})$ \\
\hline $8 \mathrm{~B}$ & $\mathrm{NO}^{+}+\mathrm{E}^{-} \rightarrow \mathrm{N}+\mathrm{O}$ & $1.321 \times 10^{-9} \mathrm{~T}^{-1.187}$ \\
\hline 9 & $\mathrm{~N}+\mathrm{E}^{-} \rightarrow \mathrm{N}^{+}+2 \mathrm{E}^{-}$ & $8.434 \times 10^{-14} \exp (-121000 / \mathrm{T})$ \\
\hline 10 & $\mathrm{O}+\mathrm{E}^{-} \rightarrow \mathrm{O}^{+}+2 \mathrm{E}^{-}$ & $1.054 \times 10^{-14} \exp (-106200 / \mathrm{T})$ \\
\hline $11 \mathrm{~F}$ & $\mathrm{~N}_{2}+\mathrm{O}^{+} \rightarrow \mathrm{O}+\mathrm{N}_{2}^{+}$ & $1.511 \times 10^{-18} \mathrm{~T}^{0.360} \exp (-22800 / \mathrm{T})$ \\
\hline $11 \mathrm{~B}$ & $\mathrm{O}+\mathrm{N}_{2}^{+} \rightarrow \mathrm{N}_{2}+\mathrm{O}^{+}$ & $1.978 \times 10^{-18} \mathrm{~T}^{0.109}$ \\
\hline $12 \mathrm{~F}$ & $\mathrm{NO}+\mathrm{O}^{+} \rightarrow \mathrm{O}_{2}+\mathrm{N}^{+}$ & $2.324 \times 10^{-25} \mathrm{~T}^{1.900} \exp (-15300 / \mathrm{T})$ \\
\hline $12 \mathrm{~B}$ & $\mathrm{O}_{2}+\mathrm{N}^{+} \rightarrow \mathrm{NO}+\mathrm{O}^{+}$ & $2.443 \times 10^{-26} \mathrm{~T}^{2.102}$ \\
\hline $13 \mathrm{~F}$ & $\mathrm{O}_{2}+\mathrm{NO}^{+} \rightarrow \mathrm{NO}+\mathrm{O}_{2}^{+}$ & $3.985 \times 10^{-17} \mathrm{~T}^{0.410} \exp (-32600 / \mathrm{T})$ \\
\hline $13 \mathrm{~B}$ & $\mathrm{NO}+\mathrm{O}_{2}^{+} \rightarrow \mathrm{O}_{2}+\mathrm{NO}^{+}$ & $6.195 \times 10^{-16} \mathrm{~T}^{-0.050}$ \\
\hline $14 \mathrm{~F}$ & $\mathrm{~N}+\mathrm{NO}^{+} \rightarrow \mathrm{O}+\mathrm{N}_{2}^{+}$ & $1.195 \times 10^{-16} \exp (-35500 / \mathrm{T})$ \\
\hline $14 \mathrm{~B}$ & $\mathrm{O}+\mathrm{N}_{2}^{+} \rightarrow \mathrm{N}+\mathrm{NO}^{+}$ & $1.744 \times 10^{-18} \mathrm{~T}^{0.302}$ \\
\hline $15 \mathrm{~F}$ & $\mathrm{O}+\mathrm{NO}^{+} \rightarrow \mathrm{O}_{2}+\mathrm{N}^{+}$ & $1.660 \times 10^{-18} \mathrm{~T}^{0.500} \exp (-772000 / \mathrm{T})$ \\
\hline $15 \mathrm{~B}$ & $\mathrm{O}_{2}+\mathrm{N}^{+} \rightarrow \mathrm{O}+\mathrm{NO}^{+}$ & $2.192 \times 10^{-17} \mathrm{~T}^{0.114}$ \\
\hline $16 \mathrm{~F}$ & $\mathrm{~N}+\mathrm{O}_{2}^{+} \rightarrow \mathrm{O}_{2}+\mathrm{N}^{+}$ & $1.444 \times 10^{-16} \mathrm{~T}^{0.140} \exp (-28600 / \mathrm{T})$ \\
\hline $16 \mathrm{~B}$ & $\mathrm{O}_{2}+\mathrm{N}^{+} \rightarrow \mathrm{N}+\mathrm{O}_{2}^{+}$ & $4.993 \times 10^{-18} \mathrm{~T}^{-0.004}$ \\
\hline $17 \mathrm{~F}$ & $\mathrm{~N}_{2}+\mathrm{O}_{2}^{+} \rightarrow \mathrm{O}_{2}+\mathrm{N}_{2}^{+}$ & $1.644 \times 10^{-17} \exp (-40700 / \mathrm{T})$ \\
\hline $17 \mathrm{~B}$ & $\mathrm{O}_{2}+\mathrm{N}_{2}^{+} \rightarrow \mathrm{N}_{2}+\mathrm{O}_{2}^{+}$ & $4.589 \times 10^{-18} \mathrm{~T}^{-0.037}$ \\
\hline $18 \mathrm{~F}$ & $\mathrm{~N}+\mathrm{NO}^{+} \rightarrow \mathrm{N}_{2}+\mathrm{O}^{+}$ & $5.645 \times 10^{-17} \mathrm{~T}^{-1.080} \exp (-12800 / \mathrm{T})$ \\
\hline 18B & $\mathrm{N}_{2}+\mathrm{O}^{+} \rightarrow \mathrm{N}+\mathrm{NO}^{+}$ & $3.970 \times 10^{-18} \mathrm{~T}^{-0.710}$ \\
\hline $19 \mathrm{~F}$ & $\mathrm{O}+\mathrm{NO}^{+} \rightarrow \mathrm{N}+\mathrm{O}_{2}^{+}$ & $1.195 \times 10^{-17} \mathrm{~T}^{0.290} \exp (-48600 / \mathrm{T})$ \\
\hline 19B & $\mathrm{N}+\mathrm{O}_{2}^{+} \rightarrow \mathrm{O}+\mathrm{NO}^{+}$ & $8.918 \times 10^{-13} \mathrm{~T}^{-0.969}$ \\
\hline $20 \mathrm{~F}$ & $\mathrm{O}+\mathrm{O}_{2}^{+} \rightarrow \mathrm{O}_{2}+\mathrm{O}^{+}$ & $6.641 \times 10^{-18} \mathrm{~T}^{-0.09} \exp (-18600 / \mathrm{T})$ \\
\hline $20 \mathrm{~B}$ & $\mathrm{O}_{2}+\mathrm{O}^{+} \rightarrow \mathrm{O}+\mathrm{O}_{2}^{+}$ & $4.993 \times 10^{-18} \mathrm{~T}^{-0.004}$ \\
\hline $21 \mathrm{~F}$ & $\mathrm{~N}_{2}+\mathrm{N}^{+} \rightarrow \mathrm{N}+\mathrm{N}_{2}^{+}$ & $1.660 \times 10^{-18} \mathrm{~T}^{0.500} \exp (-12100 / \mathrm{T})$ \\
\hline $21 \mathrm{~B}$ & $\mathrm{~N}+\mathrm{N}_{2}^{+} \rightarrow \mathrm{N}_{2}+\mathrm{N}^{+}$ & $2.343 \times 10^{-14} \mathrm{~T}^{-0.610}$ \\
\hline
\end{tabular}


Table 4: Comparison of surface heat flux predicted by the DSMC and DSMC-PIC models, $2 \times 10^{14} \mathrm{~m}^{-3}$ freestream case.

\begin{tabular}{lccc}
\hline \hline Model & charged particle heat flux $\left(\mathrm{W} / \mathrm{m}^{2}\right)$ & total heat flux $\left(\mathrm{W} / \mathrm{m}^{2}\right)$ & $\%$ total heat flux \\
\hline DSMC & $1.3 \times 10^{-2}$ & $5.4 \times 10^{-1}$ & $3 \%$ \\
DSMC-PIC & $6.6 \times 10^{-2}$ & $6.1 \times 10^{-1}$ & $11 \%$ \\
\hline \hline
\end{tabular}

Table 5: Comparison of surface heat flux predicted by the DSMC and DSMC-PIC models, $2 \times 10^{17} \mathrm{~m}^{-3}$ freestream case with $1000 \times m_{e}$.

\begin{tabular}{lccc}
\hline \hline Model & charged particle heat flux $\left(\mathrm{W} / \mathrm{m}^{2}\right)$ & total heat flux $\left(\mathrm{W} / \mathrm{m}^{2}\right)$ & $\%$ total heat flux \\
\hline DSMC & 28 & 502 & $6 \%$ \\
DSMC-PIC & 58 & 581 & $10 \%$ \\
\hline \hline
\end{tabular}




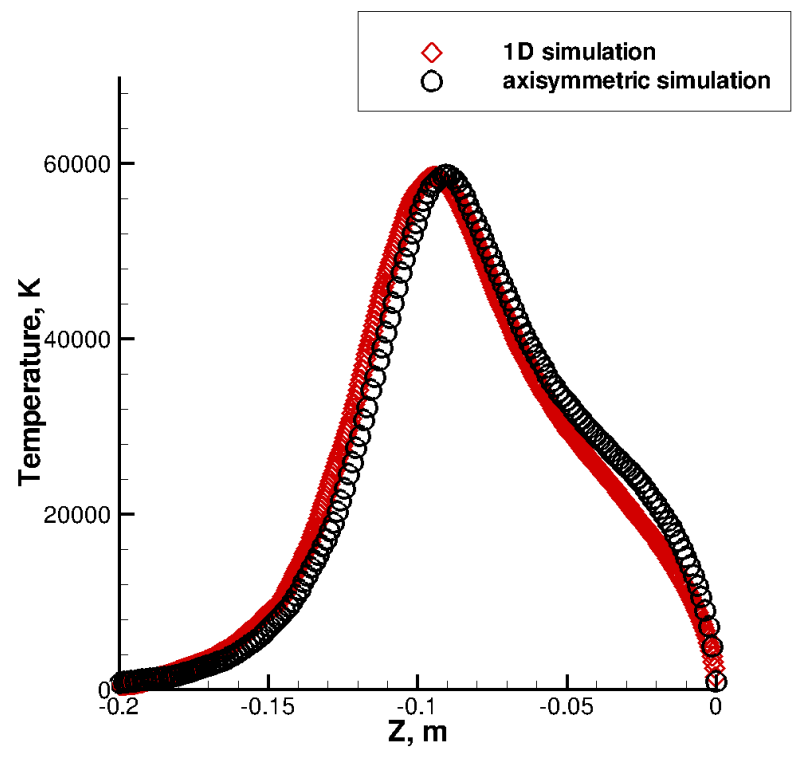

Figure 1: Translational temperatures along the stagnation streamline, FIRE II, $85 \mathrm{~km}$.

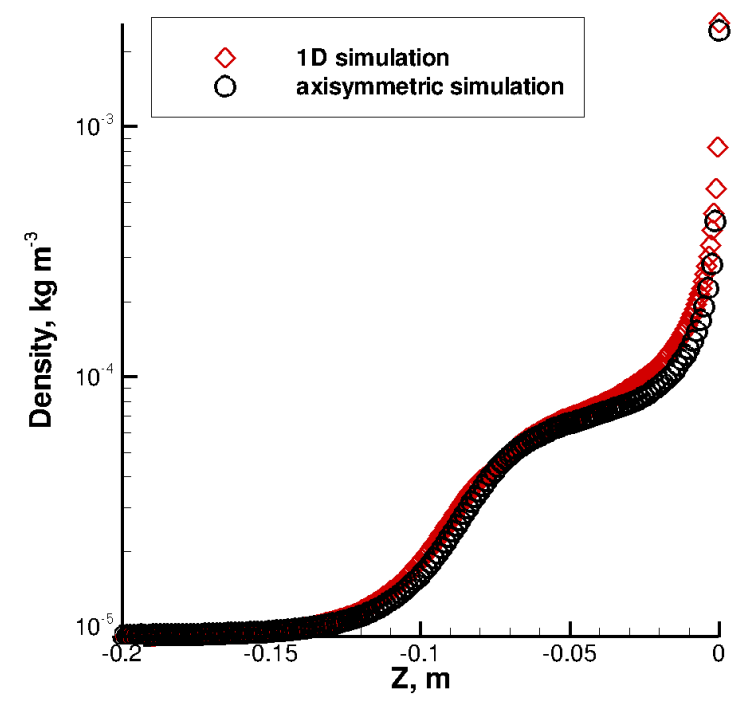

Figure 2: Mass densities along the stagnation streamline, FIRE II, $85 \mathrm{~km}$. 


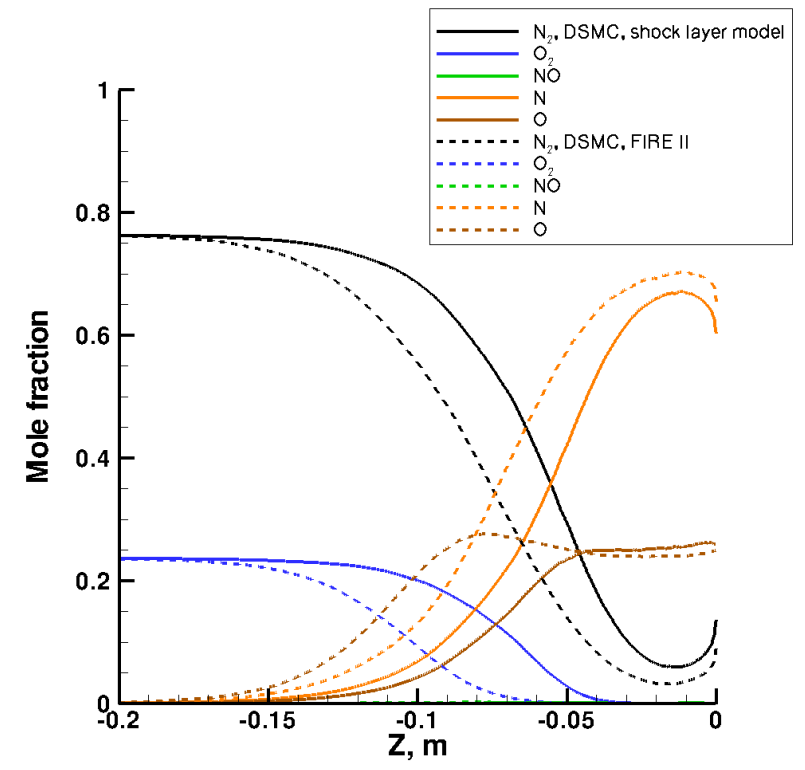

Figure 3: Mole fractions of neutral species along the stagnation streamline, $2 \times 10^{14} \mathrm{~m}^{-3}$ freestream case and FIRE II $85 \mathrm{~km}$ results.

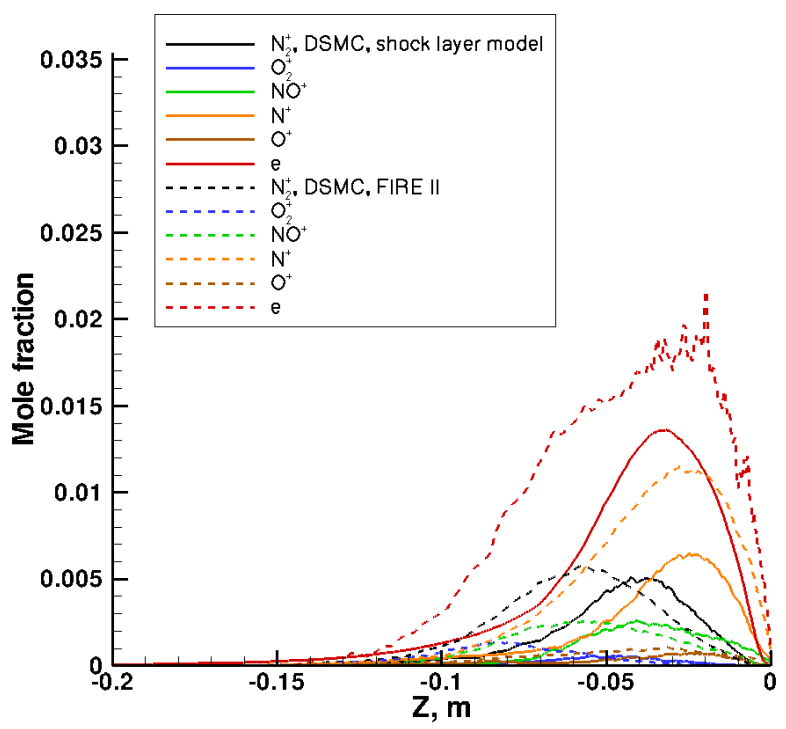

Figure 4: Mole fractions of charged species along the stagnation streamline, $2 \times 10^{14} \mathrm{~m}^{-3}$ freestream case and FIRE II $85 \mathrm{~km}$ results. 

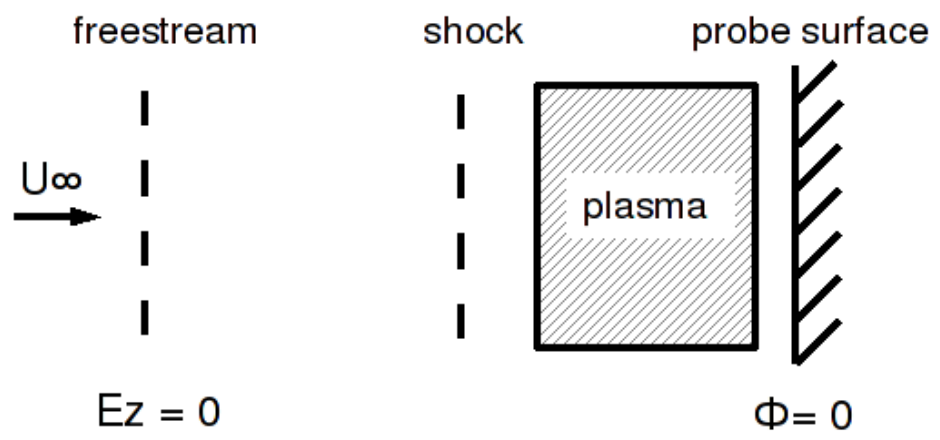

Figure 5: Schematic of the shock layer model.

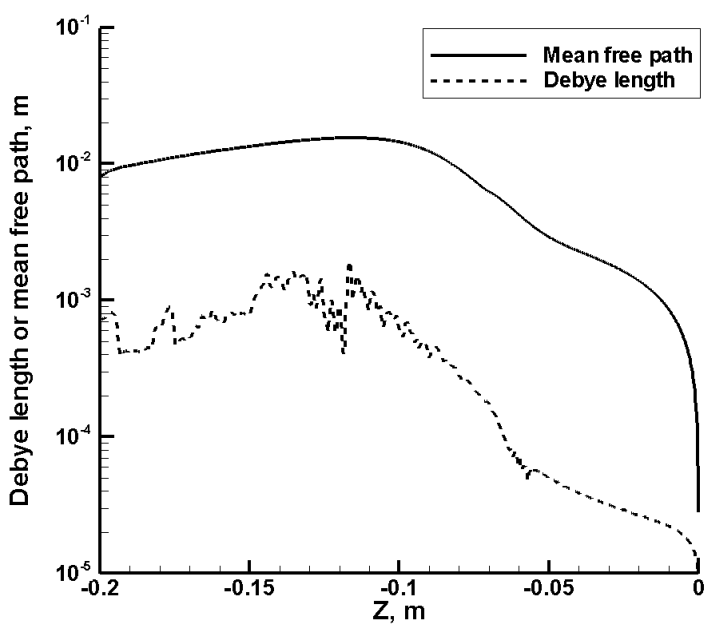

Figure 6: Debye length and mean free path along the stagnation streamline for the simulation with 16000 cells. 


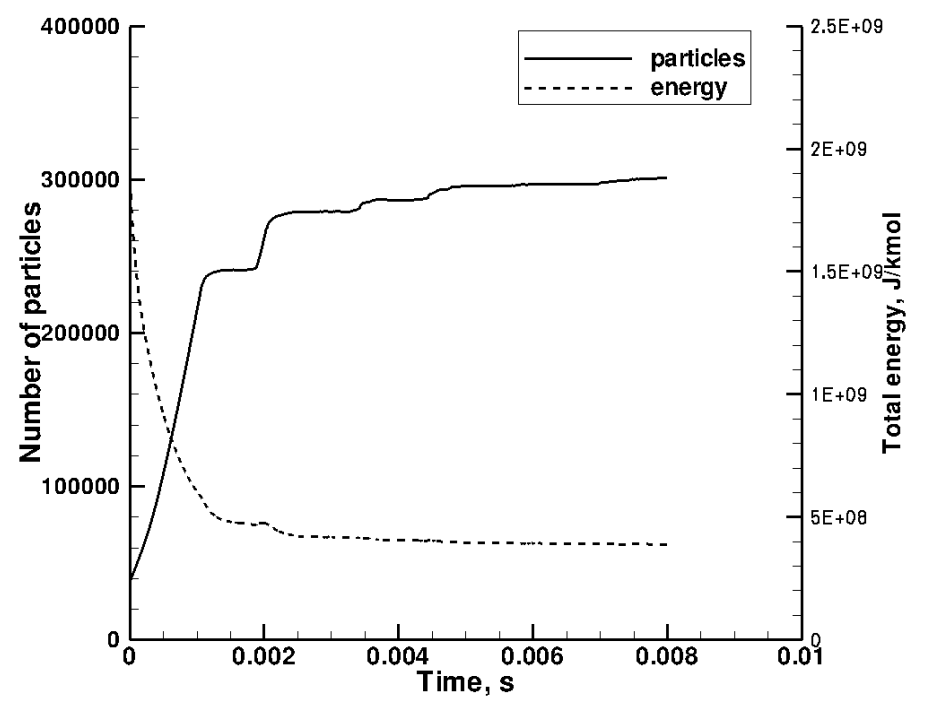

Figure 7: Number of simulator particles and total energy in the domain during a simulation, $2 \times 10^{14} \mathrm{~m}^{-3}$ freestream case.

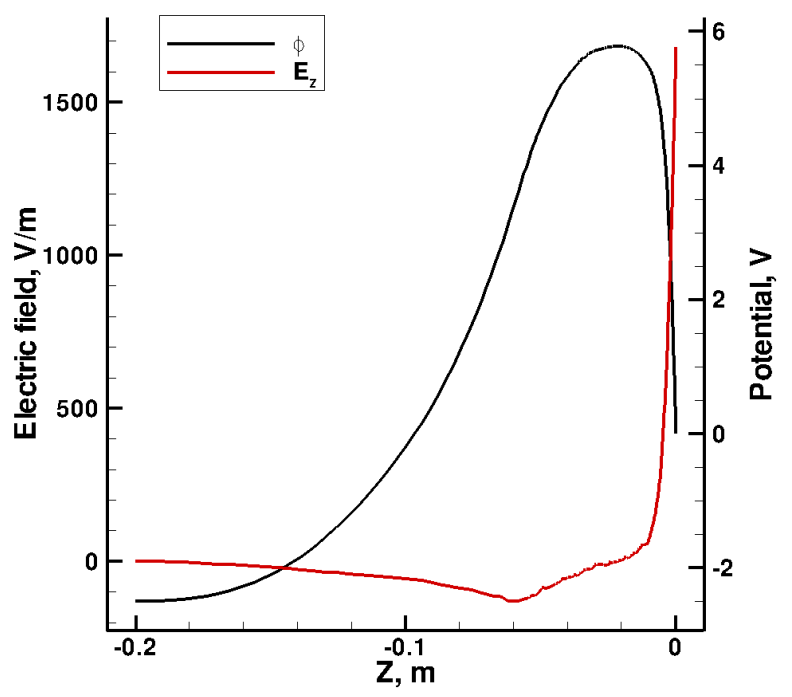

Figure 8: Electric and potential fields, $2 \times 10^{14} m^{-3}$ freestream case. 


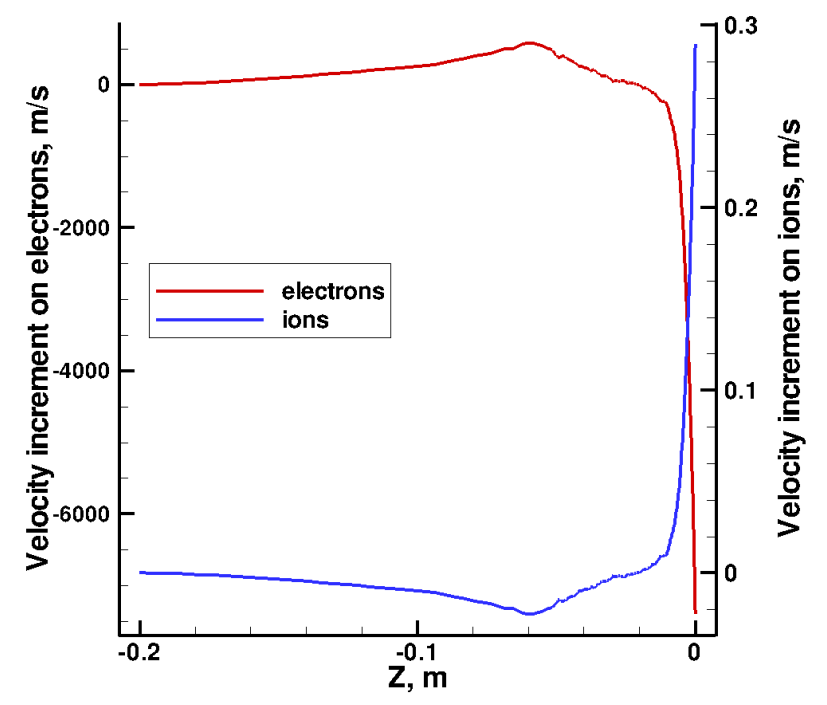

Figure 9: Velocity increment on charged particles due to acceleration by the electric field, $2 \times 10^{14} \mathrm{~m}^{-3}$ freestream case.

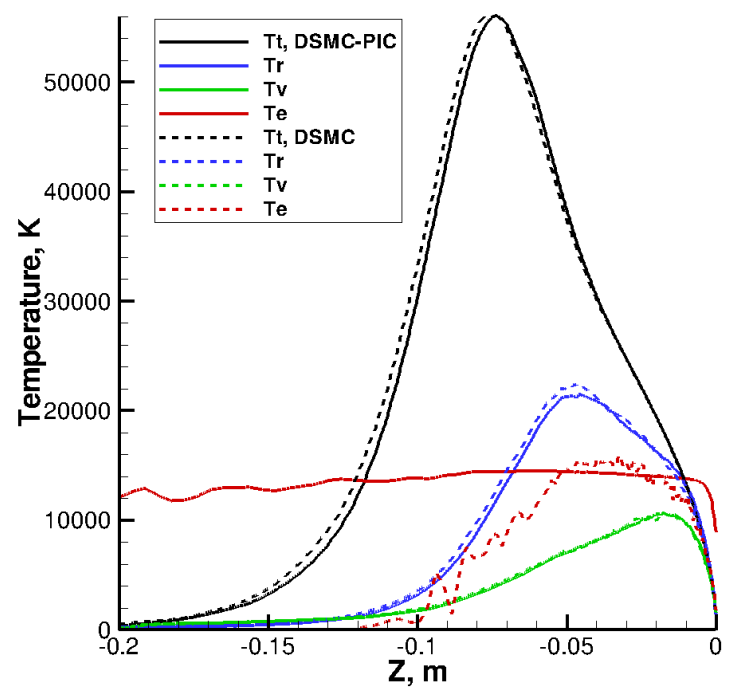

Figure 10: Temperatures along the stagnation streamline, $2 \times 10^{14} \mathrm{~m}^{-3}$ freestream case. 


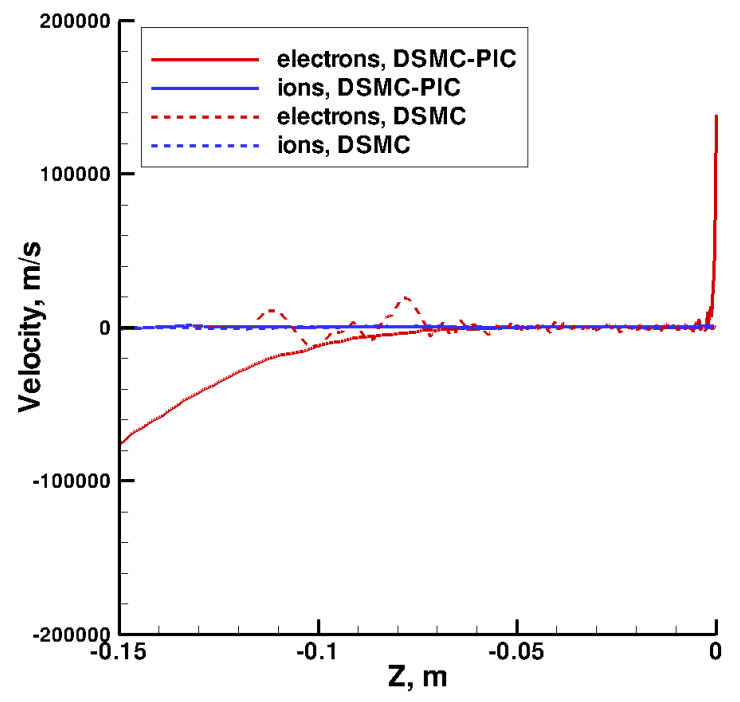

Figure 11: Average velocities of charged species along the stagnation streamline, $2 \times 10^{14} \mathrm{~m}^{-3}$ freestream case.

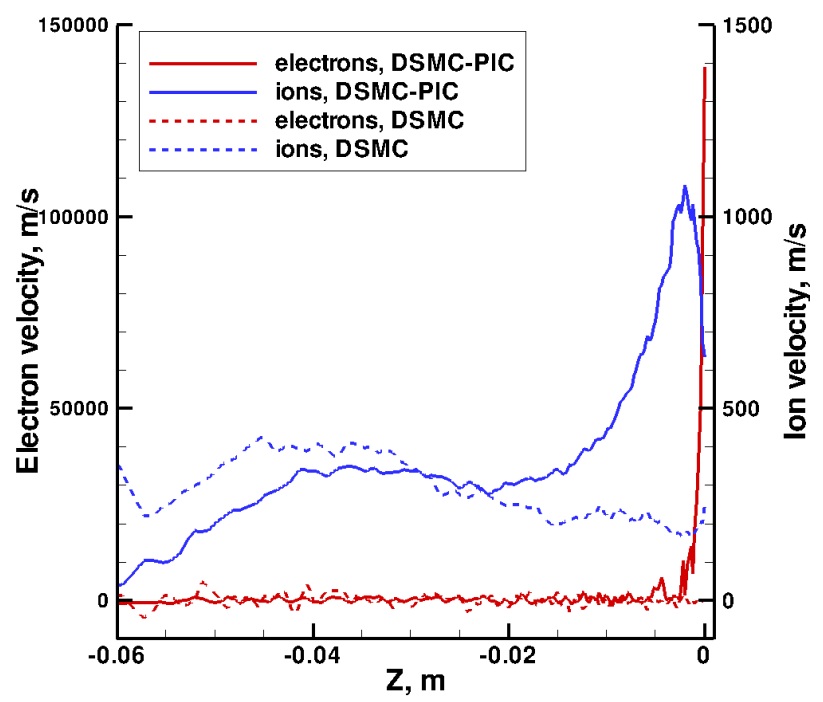

Figure 12: Average electron and ion velocities downstream of the shock, $2 \times 10^{14} \mathrm{~m}^{-3}$ freestream case. 


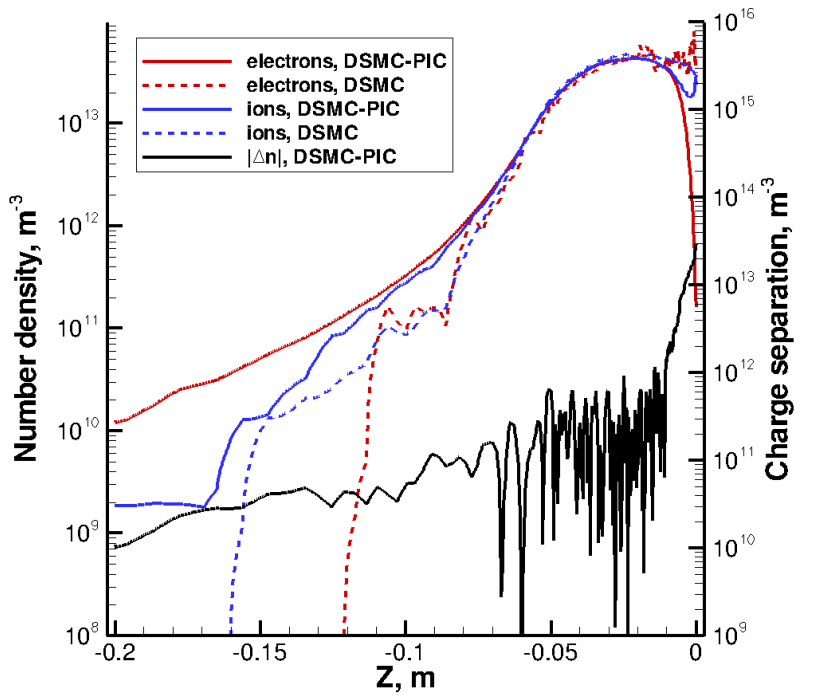

Figure 13: Number density of charged species and charge separation along the stagnation streamline, $2 \times$ $10^{14} \mathrm{~m}^{-3}$ freestream case.

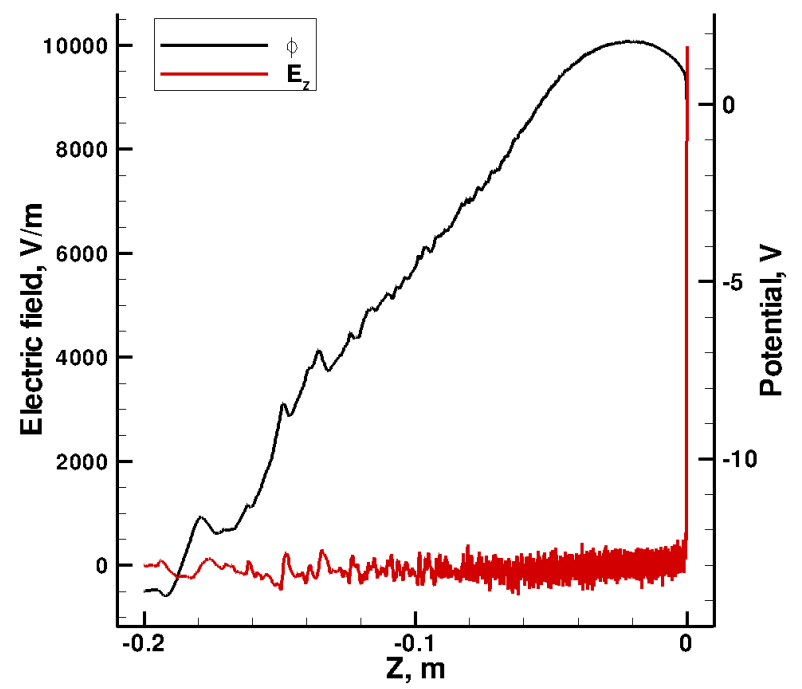

Figure 14: Electric and potential fields, $2 \times 10^{17} \mathrm{~m}^{-3}$ freestream case with $1000 \times m_{e}$. 


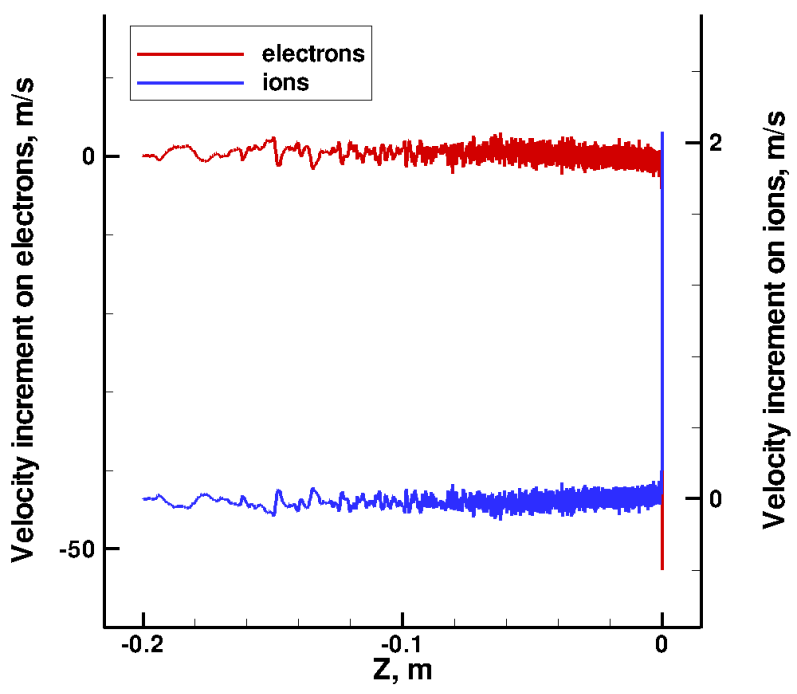

Figure 15: Velocity increment on charged particles due to acceleration by the electric field, $2 \times 10^{17} \mathrm{~m}^{-3}$ freestream case with $1000 \times m_{e}$.

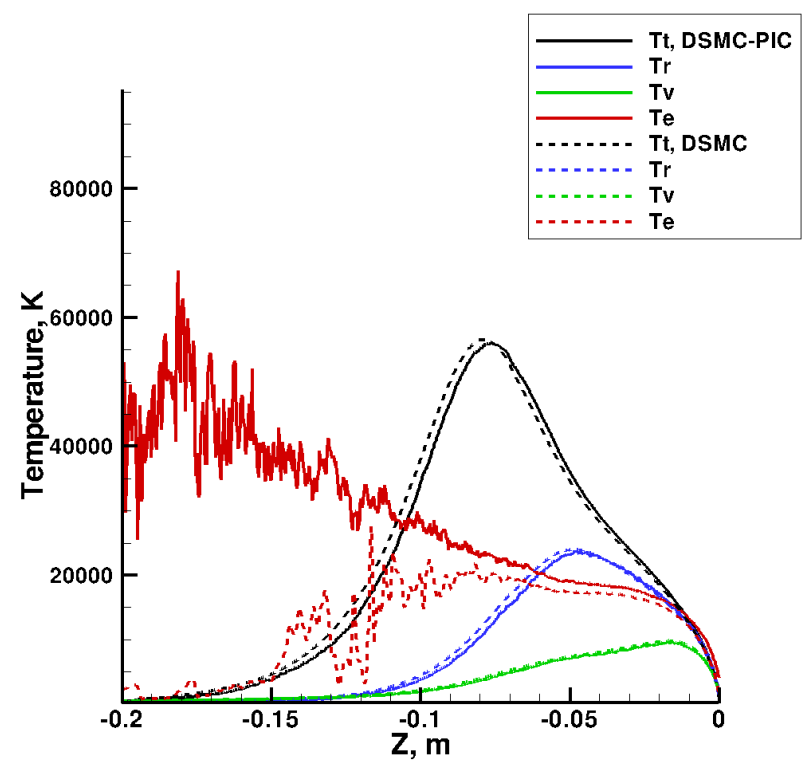

Figure 16: Temperatures along the stagnation streamline, $2 \times 10^{17} \mathrm{~m}^{-3}$ freestream case with $1000 \times m_{e}$. 


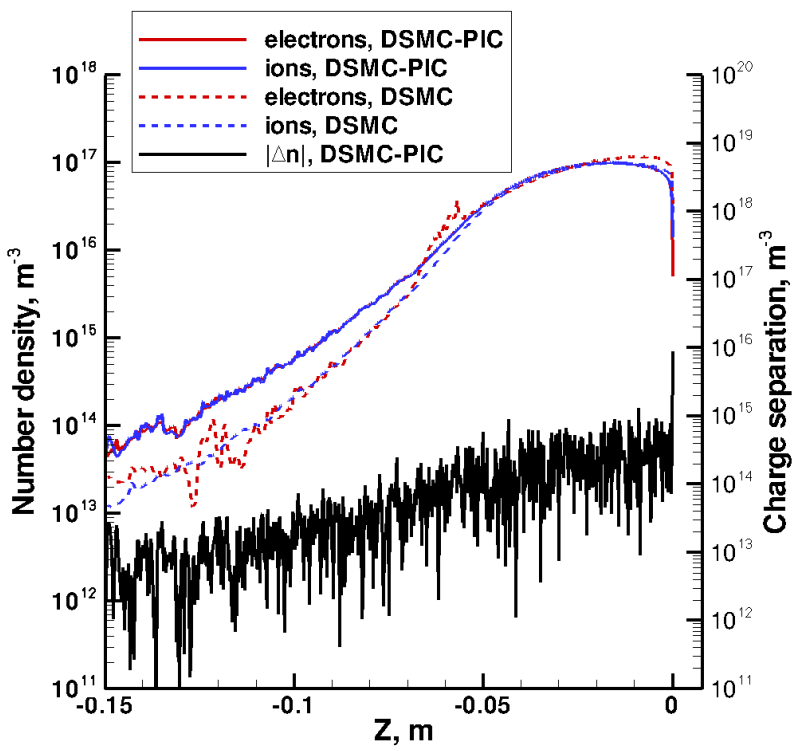

Figure 17: Number density of charged species and charge separation along the stagnation streamline, $2 \times$ $10^{17} \mathrm{~m}^{-3}$ freestream case with $1000 \times m_{e}$.

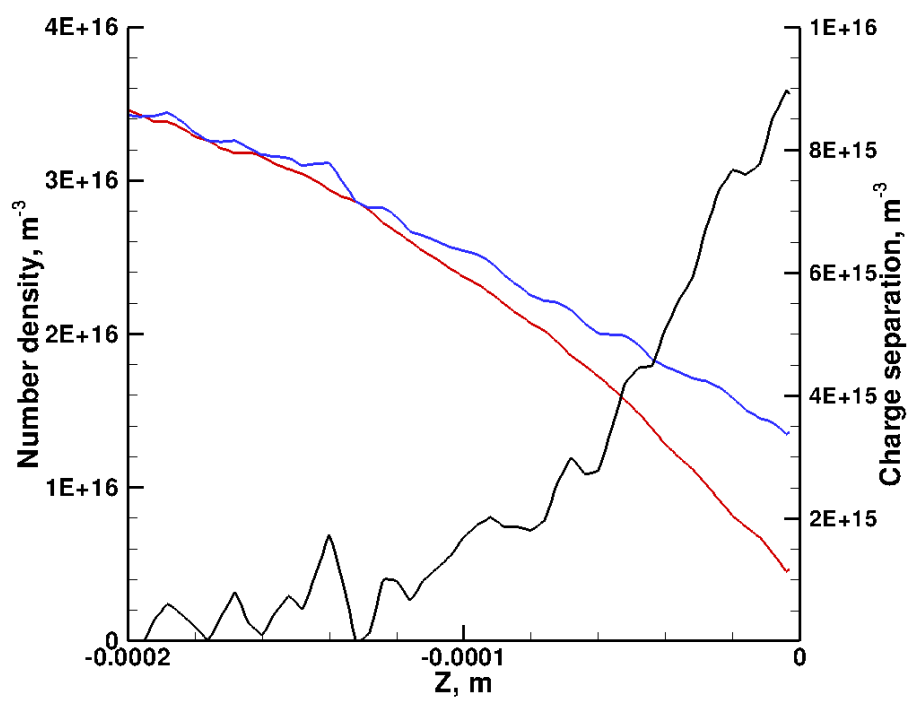

Figure 18: Number density of charged species and charge separation in the sheath, $2 \times 10^{17} \mathrm{~m}^{-3}$ freestream case with $1000 \times m_{e}$. 